\title{
Ten Principles for Power Sector Transformation in Emerging Economies
}

AUTHORS

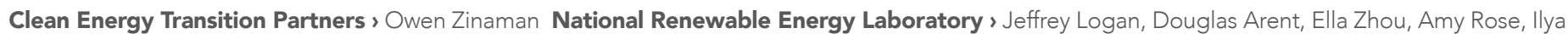

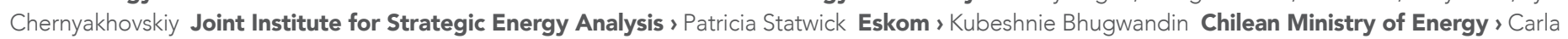
Coronado, Marco Peirano, Francisco Martinez-Conde del Campo Brazilian Energy Research Office (EPE) > Glaysson de Mello Muller, Maria Cecilia

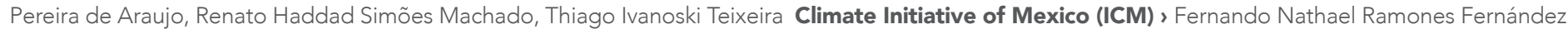

\section{Power System Transformation Principles}

Principles for emerging economy decision makers to consider while pursuing power sector transformation pathways, organized into three categories:

\section{Foundations of Power}

\section{System Transformation}

1. Power System Transformation Benefits from Strong Leadership and Vision.

2. Policy and Regulatory Certainty and Consistency are Critical Enablers of Power System Transformation, Helping to Secure Financing and Promote Utility Financial Sustainability.

3. Efforts to Enhance Institutional and Workforce Capacity are Central to Power System Transformation.

4. Charting Transformation Pathways Involves the Orchestration of a Diverse Portfolio of Actions.

\section{CLEAN ENERGY}

$M$ I $N$ I S T E R I A L Advancing Clean Energy Together

\section{Accelerating Power System Transformation}

5. Strategic Partnership Between the Public and Private Sectors Can Help Jump-start Power System Transformation.

6. Power System Transformation is Enabled by Good Data and Analytics to Evaluate a Wider Set of Pathways and Advanced Information Systems to Operate the Power System Efficiently and Reliably.

7. Auctions are Emerging as a Global Best Practice Mechanism for Generation Procurement; However, They May Take Multiple Cycles to Yield Desired Results.

8. Modern Power Systems Focus on Flexibility as a Key Resource.

Moving Forward Inclusively with Power System Transformation

9. In the Face of New Technologies and Evolving Power System Requirements, New Administrative Efforts are Likely Needed to Ensure Power System Transformation is Fair and Inclusive.

10. Power System Transformation Efforts Can Promote More Socially Equitable Development.

Acknowledgments $>$ This working paper was prepared jointly by the 21st Century Power Partnership and the National Renewable Energy Laboratory. The paper presents findings from a series of dialogues between the National Renewable Energy Laboratory and stakeholders of the 21st Century Power Partnership, and reflects the summation of multiple years of experience directly supporting emerging economy power system transformation efforts through the 21st Century Power Partnership's numerous country technical assistance programs. This effort has been jointly supported by the Children's Investment Fund Foundation, the U.S. Department of Energy, and the Hewlett Foundation. 


\section{Introduction}

Access to reliable, affordable electricity is a key driver of economic growth in modern economies. The electric power sector, once a predictable and slowmoving industry, is now a complex system undergoing rapid transformation. Countries are in various stages of reforming and transforming their power sectors to better incorporate modern technologies, assure reliability and affordability, reduce harmful air emissions, meet a wide range of environmental goals, and achieve critical developmental objectives.

Whether power sector transitions are being managed by a central government or being pursued in a more decentralized manner, charting a path towards the modernization of the power sector is a complex task. Strong and well-informed leadership is required to navigate the myriad political, financial, and technical challenges of power sector transformation. At a high level, the role of decision makers is to make transitions administratively smooth, socially equitable, economically efficient, more environmentally sustainable, and aligned with the broader public interest as locally defined.

\section{Power System Transformation Principles}

This document henceforth offers action-oriented principles for emerging economy decision makers to consider while pursuing power sector transformation (PST) pathways. They are organized into three categories as presented below:

\section{Foundations of Power System Transformation-} important framework conditions for charting PST pathways

\section{Accelerating Power System Transformation-} common strategies and approaches for accelerating PST efforts

\section{Moving Forward Inclusively with Power System Transformation-considerations for fairness and equity in PST efforts.}

Although the principles offered in this document are informed by a range of international experiences and intended to offer useful insights to power system leaders across the world, it is also important to note that there is no simple progression or playbook for PST. Rather, it is a highly context-dependent process, and the exact set of principles that are suitable for a certain country may have limitations in others.

\section{TEXT BOX 1: What is Power System Transformation?}

Power system transformation (PST) is the active process of creating the policy, market, and regulatory environmentsas well as establishing operational and planning practicesthat accelerate investment, innovation, and deployment to realize smart, efficient, resilient, and environmentally sound power systems (21CPP and IEA 2018). Power systems are a complex and interrelated web of physical infrastructure, institutions, processes, actors, and interests, and any effort to meaningfully steer their transformation greatly benefits from actions that far transcend the development of new infrastructure. Equally important are institutions, workforces, and market and regulatory frameworks that transition in a deliberate and coordinated manner, underpinned by strong and stable leadership. 


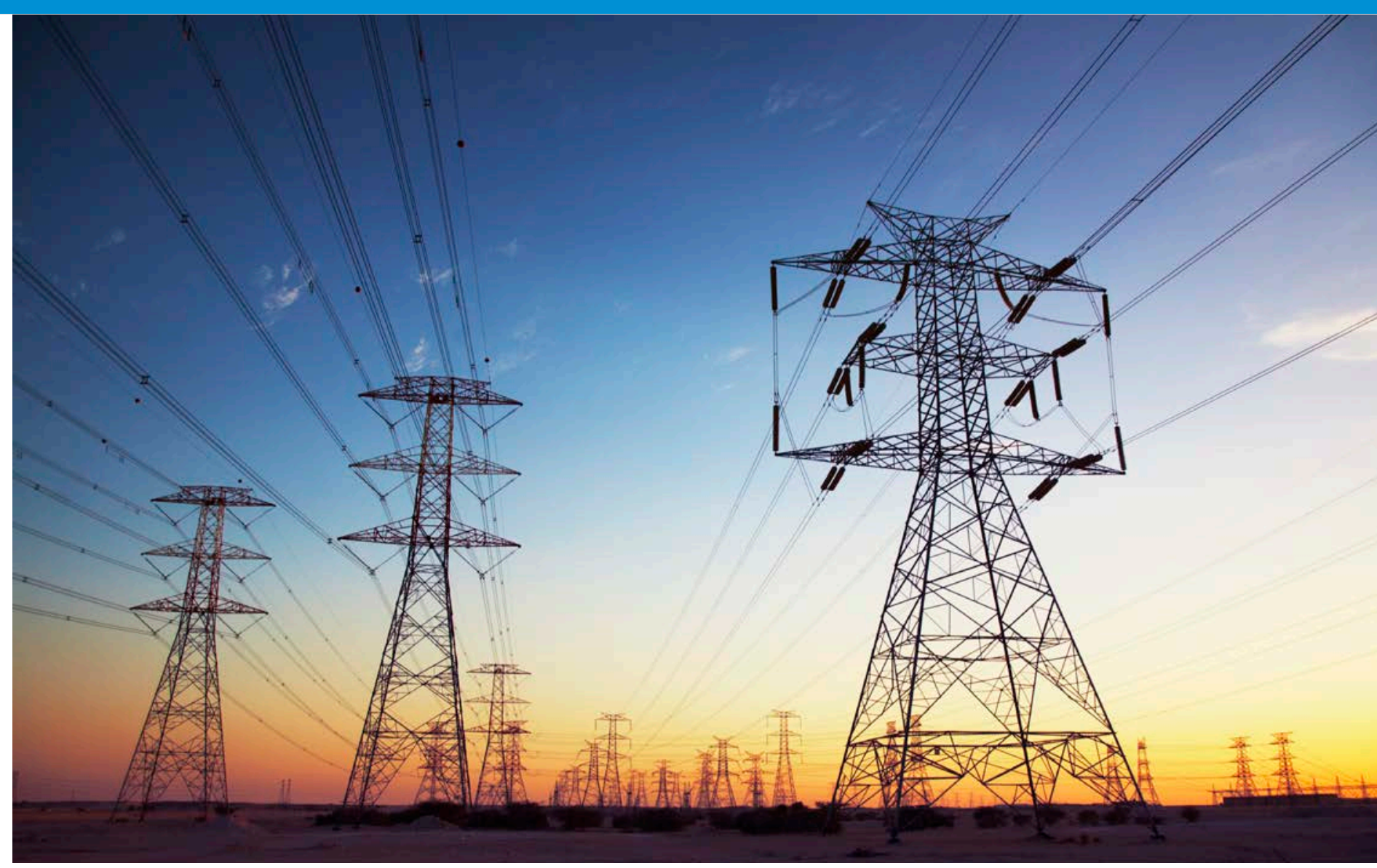

\section{Foundations of Power System Transformation}

\section{Power System Transformation Benefits from Strong Leadership and Vision}

Charting a course for PST in emerging economies requires political will, vision, and leadership. The challenges of managing traditional power sectors-ranging from revenue sufficiency and equitable tariff design to coordinated planning and expanded quality of service-may seem daunting even before considering new challenges associated with a more decentralized, digitized, and environmentally sound grid. Yet PST can offer new opportunities to exercise bold leadership and break free from the traditional stumbling blocks of power sector governance.

Effective PST is enabled by strong governance to streamline communication, coordination, and collaboration across a range of government agencies, and to ensure transparency of information and clear allocations of responsibilities across stakeholders (see Principle \#4). Turning targets and goals into real, on-the-ground actions is most often realized via champions at the highest level who drive change and overcome established causes and conditions that may impede progress. Innovative decision pathways and "learning-by-doing" may involve risk-taking and expenditure of social capital. A robust vision of PST requires clearly articulated goals and tireless pursuit of affordability, reliability, and energy access to drive inclusive economic growth.

A clearly defined and well-articulated long-term vision for the electricity sector can provide transparency and promote buy-in from across government agencies, private sector stakeholders, and the general public. This calls for careful planning and transparent assessment of potential PST pathways-informed by gap analyses that identify 
both barriers to change and requisite actions to support transformation-to establish an effective long-term vision that is grounded in real-world conditions and responds to existing needs and challenges. An effective long-term

TEXT BOX 2: Why Power System Transformation?

PST offers an unprecedented opportunity for improved national energy security and energy price reductions, as modern power system resources are revealing new pathways to meeting electricity sector goals. The opportunity to achieve the trifecta of affordability, reliability, and access to energy in emerging economies with modern and environmentally friendly technologies has perhaps never been larger. This is due in large part to the growing ubiquity of low-cost wind and solar photovoltaic energy resources, which are poised to become a defining feature of many power systems. These resources help to lower energy prices while also reducing long-term exposure to fuel price volatility and reliance on energy imports; in some cases, they can also create additional energy export opportunities. Other important trends shaping PST globally include the rise of distributed energy resources (DERs), increasing use of information and communication technologies to coordinate power system operations and enroll responsive demand-side resources, the decreasing costs of battery energy storage systems, and increased coupling between the power sector and other economic sectors (e.g., vehicle electrification in the transport sector).

Power system transformation also presents a substantial opportunity to fuel economic growth and create new employment opportunities. Importantly, many of these jobs can positively impact rural communities that may have otherwise been left behind by economic development in urban centers, creating well paying jobs that cannot be exported and providing land-use payments and new sources of tax revenue. Although larger infrastructure projects such as wind or solar farms sometimes encounter resistance from the local communities where they are located, decision makers can step in at various stages to ensure that local communities become more active partners in these projects and receive both immediate and longterm benefits from their participation. vision benefits from strong leadership to articulate goals; include, educate, and motivate stakeholders; and set a clear and streamlined course for action.

Identifying and catalyzing new leadership to spearhead PST may largely depend on the right person emerging at the right time, but stakeholders can incentivize such leadership through partnerships and the sharing of lessons learned. Mexico's energy sector reforms, for example, are a good example of how political leadership can both drive a discussion to motivate PST and establish a new culture of electricity sector planning, procurement, and system operations.

\section{Policy and Regulatory Certainty and Consistency are Critical Enablers of Power System Transformation, Helping to Secure Financing and Promote Utility Financial Sustainability}

Sound policy and regulatory frameworks can in many respects be considered the "bedrock" of PST. ' At a high level, good policy and regulation can promote utility financial viability and the overall financial health for the sector, help to encourage public and market confidence that policy and regulatory processes are fair and nondiscriminatory, and ensure a steady stream of financing is available to maintain existing infrastructure and pursue PST pathways. In practice, there are several key aspects of this "bedrock" for decision makers to consider. These include, among others:

- Publicly stated long-term PST goals that can adapt to evolving technology and macroeconomic landscapes and avoid retroactive policy changes that threaten sector stability. As PST goals are being established, ensuring that a process exists to foster transparency and solicit public input is key.

\footnotetext{
${ }^{1}$ The concept of policy and regulatory "bedrock" was originally coined in IEA-RETD (2016) in the context of renewable energy. This working paper expands that definition to power system transformation.
} 
- Responsive electricity pricing processes that can adapt to emerging technology trends and ensure the procedure to adjust tariffs moves quickly and rationally when higher utility costs are incurred due to inflation, rising fuel costs, a lack of bill collection, ${ }^{2}$ poor utility operating performance, or other factors. ${ }^{3}$ Transparency and stakeholder engagement in these processes can be key.

\section{- Well-staffed and adequately funded regulatory} agencies that are focused on promoting utility operational performance through rigorous monitoring, oversight, and enforcement.

- Investment process transparency that includes clearly stated and enforced time frames for project evaluation and selection, transparent project evaluation criteria, and clearly delineated cost and risk allocation among ratepayers, utilities, and investors for generation interconnection costs.

\section{- Clear land access, project permitting, siting,} and interconnection rules that reduce investment uncertainty and associated costs while balancing environmental and social considerations.

- Strong legal frameworks that ensure contract enforcement and reduce investor perceptions of risk.

\section{Efforts to Enhance Institutional and Workforce Capacity are Central to Power System Transformation}

Decision makers cannot manage PST alone. Instead, they should invest in their supporting institutions and staff, building capacity to support reform efforts. More often than not, energy regulation and governance lag behind technological innovation, which compels forms of "institutional innovation" to play catch-up (UNU-WIDER and JISEA 2017). In this context, established power sector institutions will likely have a variety of new jobs for supporting PST efforts, from regulators addressing data ownership rights, to certification bodies creating new communication protocols, to utility planners integrating generation and network expansion exercises, to system operators integrating variable renewable energy. Each institution will require clear roles and responsibilities, the legal and political authority to pursue change, and the financial and personnel resources to effectively undertake implementation. Capacity building efforts, however, do not stop at institutions-energy research and analysis stakeholders, investors, developers, and even the general public will significantly benefit from direct engagement from government to build momentum behind reform efforts. This engagement may take the form of public consultations on proposed PST goals, energy plans, or regulatory reforms, or may occur through the release of government reports that help define issues and opportunities for PST. The academic community would also benefit from clear guidance from government on the new skill sets and knowledge bases required for $21^{\text {st }}$ century power sector jobs to inform course offerings and curriculum design.

Furthermore, decision makers can help support the creation of effective institutional networks, providing guidance to key institutions on their exact jurisdiction and set of responsibilities, and elucidating how they are expected to communicate, share information, and coordinate responsibilities with others in pursuit of shared PST goals. Charting of power sector reforms also provides an excellent opportunity for building or retooling institutional structures to perform new tasks (e.g., the redesign of a regulatory body to oversee further private sector competition in generation, as occurred following Mexico's 2015 Energy Transition Law). Decision makers can help seek out the right capacity-building resources to get institutions off on the right foot-there are many ways for emerging

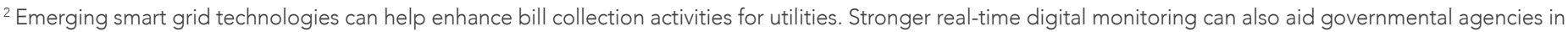

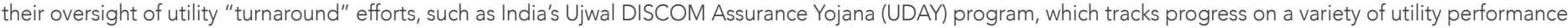
metrics and offers performance-based regulatory incentives to promote progress (21CPP and RAP 2017).

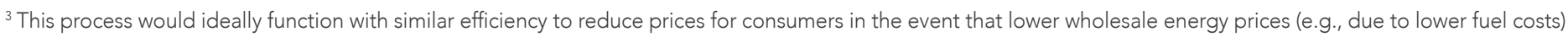
occurred.
} 
economy governments to invest in their institutions and labor forces to build relevant skill sets useful for $21^{\text {st }}$ century power sector jobs, and decision makers can consider a variety of actions for engagement that fit their specific goals, priorities, and available resources. Many international engagement mediums exist that support power sector capacity-building activities, including through the Clean Energy Ministerial (CEM).

\section{Charting Transformation Pathways Involves the Orchestration of a Diverse Portfolio of Actions}

As mentioned previously, the opportunity space for PST is growing. In order to evaluate the full suite of technology options available, technical expertise and financial resources are required (see Principle \#3), a variety of data need to be collected and analyzed (see Principle \#6), and decision makers will likely need to lead a diverse portfolio of interrelated actions to implement reforms. The essence of leadership required to chart PST pathways is that of the symphony conductor: a variety of important aspects must be orchestrated and choreographed, not necessarily in lockstep, but ideally in harmony. These aspects include: the integration of various planning exercises (e.g., generation and transmission planning processes); modification of investment frameworks, market rules, and grid codes to expand technology access and unlock financing; incentivization of better power system operations; leadership of institutional overhauls and capacity-building efforts; leadership of public engagement efforts; orchestration of a network of participating institutions and stakeholders; and navigation of the political sphere. This suggests the need for a coordination role that policymakers are among the most suitable to assume. This role might include connecting different entities and actors, moderating between conflicting interests, or even developing capacities in the sector by directing strategic education efforts such as engaging with the financial sector to promote understanding of new energy technologies and how they might operate in the power sector. Emerging economies in particular may benefit from robust processes to oversee PST efforts and coordinate among relevant agencies. Thus the creation of new organizations or coordinating bodies may be warranted to ensure that PST efforts progress smoothly. For example, following the passage of Mexico's Energy Transition Law, the Secretariat of Energy (SENER) established the "Consultative Council for the Energy Transition." This Council has several working groups that collectively oversee all government and utility-related activities connected to the implementation of the Energy Transition Law (SENER 2019).

The signature challenge for decision makers here is not necessarily managing the number of actions, but instead navigating the dynamic interplays and interlinkages between the various aspects as the power sector evolves. For example, modifications to system operations to encourage better forecasting practices may lead to reduced reserve requirements; decision makers and their supporting regulatory institutions may need to step in to ensure that utilities integrate this new development into planning exercises and ensure that investment frameworks ultimately procure less peaking capacity, such that the full benefit of the initial forecasting improvements are ultimately realized (21CPP 2012). 


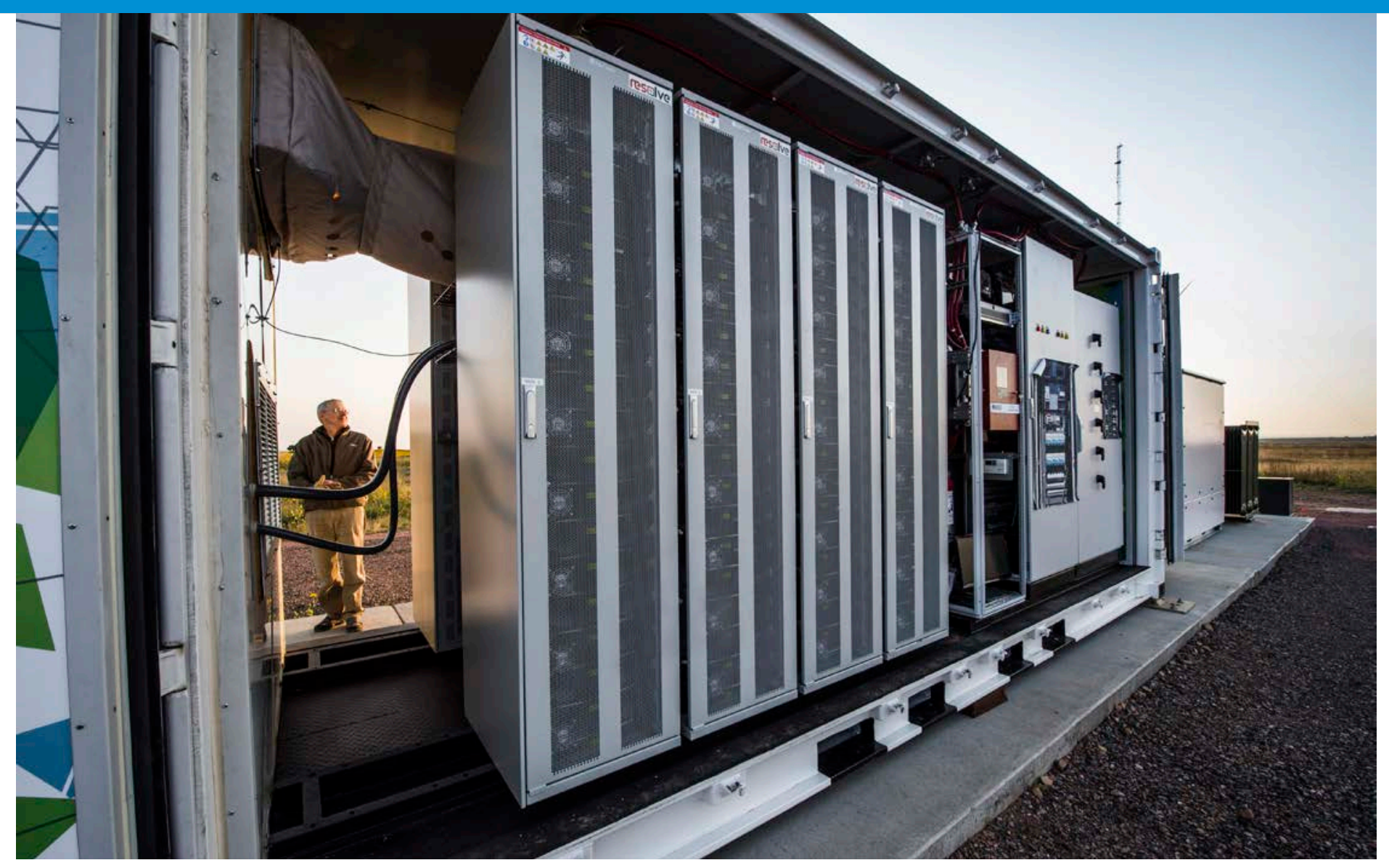

\section{Accelerating Power System Transformation Pathways}

\section{Strategic Partnership Between the Public and Private Sectors \\ Can Help Jump-start Power System Transformation}

There are a multitude of PST pathways available for consideration, all of which are influenced by the starting conditions of each power system. Key conditions include, among others, the current market organization of the power sector and the degree of stakeholder willingness to embrace and support change (21CPP 2015). Many emerging economies feature vertically integrated state-owned utilities (SOUs) as a key aspect of their starting conditions for transformation - these entities are often touted as having a "developmental role" in the economy, with the mission of providing affordable, reliable, and high-quality electricity access without the profit-seeking motives and behavior of private enterprises. Given the importance of electricity access to economic growth, decision makers may have a particular sensitivity or aversion to any discussion of transformation that involves power sector privatization or the introduction of competition, as such efforts may be perceived as leading to rising energy prices and/or excessive profiteering, and may be met with strong public opposition (Hall, Lobina, and de la Motte 2005).

Global experience, however, suggests that neither privatization nor the introduction of competition is necessarily incompatible with maintaining the developmental role of SOUs, particularly if the utility is suffering from poor operating performance. In some circumstances, competition and/or privatization in certain power market segments sectors (e.g., generation, distribution) can help break structural cycles of 
financial weakness in SOUs (World Bank 2017). On the other hand, it is important to note that privatization is neither a panacea nor a one-size-fits-all solution for shoring up SOU financial situations or pursuing PST. Global experiences with the introduction of competition and privatization are numerous, and results have been markedly mixed depending on the design of the transition and a variety of local circumstances (World Bank 2004a) (Besant-Jones 2006). ${ }^{4}$

Nevertheless, the introduction of competition may be a key instrument during PST efforts for improving a government's fiscal position, while boosting utility operational efficiencies through further transparency and accountability and expanding electricity access. Furthermore, competition can help unlock financing and unleash private sector operational efficiencies into the sector, leading to lower energy costs, while also potentially shielding ratepayers from the risk of budget overruns and construction delays from large capital infrastructure projects. In the long run, these same forces can help unlock the capital required to fuel PST. For instance, at a time when SOU Eskom has been experiencing financial challenges (SA-PBO 2017), South Africa's Renewable Energy Independent Power Producer Procurement Programme has helped to procure more than $6 \mathrm{GW}$ of new renewable energy capacity, injecting more than USD $\$ 20$ billion of private sector capital into the power sector and creating tens of thousands of jobs with no contribution from government besides an offtaker risk guarantee (SA-DOE 2018; Eberhard and Naude 2016).

\section{Power System Transformation is Enabled by Good Data and Analytics to Evaluate a Wider Set of Pathways and Advanced Information Systems to Operate the Power System Efficiently and Reliably}

Across the globe, many countries are committed to pursuing PST (CEM 2015). In the age of digitalization and ubiquitous data, power sector reforms, policies, and planning exercises, as well as power system operations, can now be better informed by data and analytics - in fact, it is quickly becoming the standard practice for charting robust, risk-adjusted pathways and supporting efficient power system operations. The opportunity for PST is larger than ever before, with a suite of new resources to consider during planning exercises, including demand-side management programs, smart grid technology deployment, electrification of end uses, weather-dependent variable renewable energy resources, storage, and the flexibilization of power plants.

As power system operational procedures modernize, there is an increasing dependence on advanced information systems that process large volumes of detailed data in real time to support efficient system operations. Modern decision-support tools that more holistically evaluate the evolving suite of technology and system solutions are similarly enabled by robust, valid data and institutional capacity to conduct and interpret appropriate analyses. This increased opportunity for PST, while offering the promise of a more affordable, resilient, and clean electricity supply, has undoubtedly made planning PST pathways a more complex task. ${ }^{5}$ For instance, traditional long-term planning techniques may not consistently consider aspects of system flexibility (see Principle \#8) in sufficient detail to recommend robust power systems pathways. In some circumstances, valuable insights may be gained from pairing appropriately granular power system operational simulations with longer-term investment tools to evaluate if proposed power systems are sufficiently flexible (21CPP and IEA 2018). With this additional analytical complexity, leadership and coordination of such tasks will undoubtedly become more complex as well. In some cases, new types of data may need to be collected to inform planning studies. For instance, with the increasing prominence of power system flexibility as a key PST issue (see Principle \#8), the Brazilian government is beginning to collect data on the flexibility constraints of their hydropower fleet.

Good planning exercises are supported by underlying institutional processes that continuously collect a range of

\footnotetext{
${ }^{4}$ If the goal of decision makers is solely to shore up utility finances, there are many strategies and measures available to do so without privatization, such as those detailed in World Bank (2004b).

${ }^{5}$ For more information on how power sector planning practices are evolving, see, e.g., 21CPP and IEA (2018), 21CPP and IEA (2017), and IRENA (2017).
} 
important data from across the power sector. These data are then periodically utilized in decision-support modeling tools to assess infrastructure investment options; these exercises allow decision makers to understand how the decision-making landscape is evolving over time and what is possible, necessary, and appropriate for power sector reform pathways. For example, in the face of growing variable renewable energy curtailment, the Chinese government ordered the collection of thermal power plant flexibility data, including an assessment of the potential for retrofitting power plants to improve flexibility. This data set was then analyzed, and ultimately included in China's 13th Five-Year Plan for the power sector, establishing a goal to retrofit much of China's 220 GW of retrofit-ready thermal capacity (NDRC 2016).

\section{Auctions are Emerging as a Global Best Practice Mechanism for Generation Procurement; However, They May Take Multiple Cycles to Yield Desired Results}

Emerging economies often must take steps to reduce investment risks in order to attract private investment. Centralized competitive generation investment frameworks, such as auctions, are emerging as a best practice method for securing the promise of low electricity prices offered by modern power system resources, while also lowering investment risks by providing longer term contracts and, in certain circumstances, government offtaker guarantees. Legacy generation procurement methods have typically relied on a regulated utility "build-own-operate" model or feed-in tariffs for private power producers. ${ }^{6}$ Under an auction framework, rather than a utility or government setting a price for energy delivery for various technologies, private sector entities are instead allowed to compete on price to determine the lowest possible power purchase agreement rate that the market will bear. These auction frameworks, along with declining technology costs, are responsible for the myriad record-breaking energy contract prices being secured across the globe, and there are a variety of key practices, success factors, and challenges for conducting auctions successfully. ${ }^{7}$ In Chile, electricity prices have plummeted since auction regulations were modified to allow the participation of variable generation sources, such as wind and solar energy (CNE 2018).

Importantly, global experience suggests that record-breaking prices do not happen overnight, and that several cycles of administratively successful auctions have led to lower costs. For instance, South Africa's Renewable Energy Independent Power Producer Procurement Programme yielded a reduction in average contracted prices between the first and third auction rounds of $42 \%$ for wind and $68 \%$ for solar photovoltaics, with both technologies' contract prices ultimately falling below the cost of existing fossil fuel generators in the country (CSIR 2017). The South African experience of cost reductions over multiple auction rounds mirrors that of many other emerging economies, including Mexico, India, China, Saudi Arabia, and others. Historically, first and second round auctions address key risks and opportunities to successfully attract first-mover developers, with decision makers accounting for the cost of launching a new market. The benefit of significant cost reductions in later auction rounds, however, tends to far outweigh the costs associated with the higher-priced first-movers.

\section{Modern Power Systems Focus on Flexibility as a Key Resource}

Flexibility is defined as the ability of a power system to balance the supply and demand of electricity across all relevant timescales, from ensuring instantaneous stability of the power system to supporting long-term security of supply. Power systems are already designed with the flexibility to manage variability and uncertainty, but requirements may grow and change over time. Driven in many contexts by the integration of variable renewable energy, increasing resource diversity, and a growing intensity and frequency of high-impact weather events, power system flexibility is an increasingly important topic for policymakers and system planners to consider. The topic continues to grow in relevance with the rise of DERs.

${ }^{6}$ See Couture et al. (2010) for an expanded discussion of feed-in tariff program design.

${ }^{7}$ Achieving a critical economic mass to successfully conduct auctions and form efficient prices can be a challenging undertaking. Chapter 4 of IRENA (2018) elaborates this in detail, organizing key factors into (1) program management factors, (2) program design factors, and (3) market factors. 
There are a variety of infrastructure options available that can boost system flexibility, ranging from power plant retrofit projects to battery energy storage to demand-side management programs. ${ }^{8}$ However, global experience suggests that major capital investments are often not required to enhance system flexibility. Instead, modifications to system operational procedures or market and regulatory incentives can unlock existing system flexibility that is often underutilized. The speed of system operations and the size, or "footprint," of system coordination are two highly influential factors that can unlock latent flexibility in the power system.

India serves as a recent success story; system operations were switched from hourly to 15-minute operations and the national grid was fully synchronized in 2013 to promote electricity trade and coordination among regions, resulting in more reliable, flexible, and cost-effective delivery of electricity (GTG 2016). ${ }^{9}$ In addition, more flexible contractual arrangements among power sector stakeholders (e.g., thermal power plants and fossil fuel supply companies) can enable power plants to operate more flexibly, while reducing power system operational costs and leaving headroom for the introduction of lower-cost resources at a later date. ${ }^{10}$ In Brazil, the government's Energy Research Office is currently analyzing the possible benefits for system expansion of altering the operations of hydropower reservoirs-which currently maximize their energy outputto supply additional system flexibility services (EPE 2018).

CEM has identified power system flexibility as a key resource for promoting PST, and has launched a global campaign with the International Energy Agency, Multilateral Wind and Solar Working Group, and the $21^{\text {st }}$ Century Power Partnership to deepen understanding of the concept and highlight various policy options to promote flexibility (CEM 2018).

\section{LAYERS OF POWER SYSTEM FLEXIBILITY}

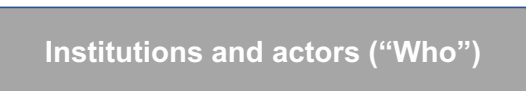

Typical decision makers

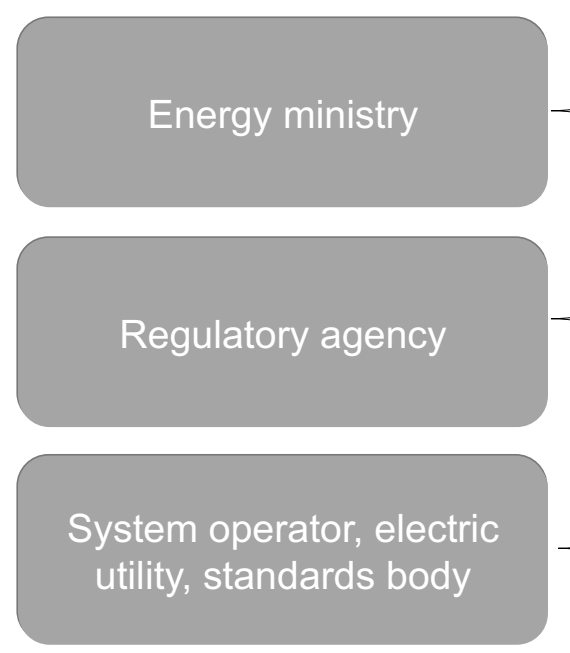

Source: 21CPP and IEA. 2019.

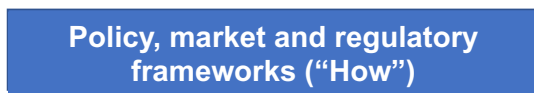

Categories of interventions
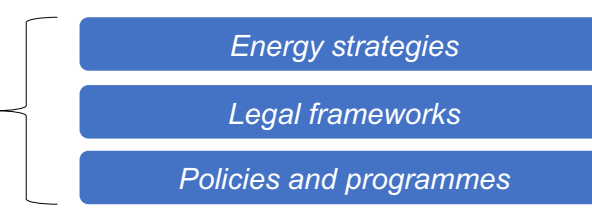

Regulatory frameworks and decisions

Power sector planning exercises

Retail electricity pricing

Power market rules and codes

System operation protocols

Connection codes

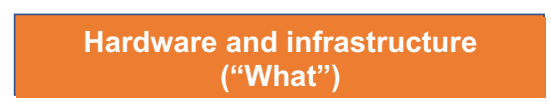

Asset types

Power plants Electricity networks
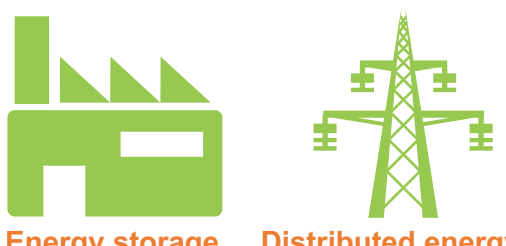

Distributed energy resources
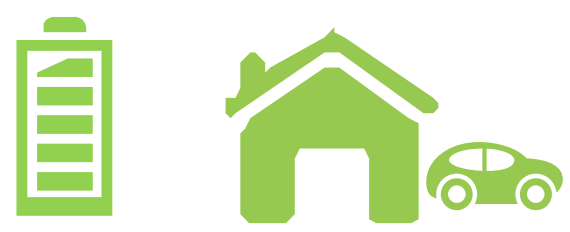

\footnotetext{
${ }^{8}$ For a more comprehensive review of flexibility hardware options, see, e.g., 21CPP and IEA (2018) and 21CPP and IEA (2019). Available at: https://webstore.iea.org/ status-of-power-system-transformation-2019

${ }^{9}$ More recently, India has been considering a transition from 15-minute operations toward 5-minute operations (FOR 2018).

${ }^{10}$ See 21 CPP and IEA (2018) for a comprehensive review of policy, regulatory, and market incentives for promoting investment in system flexibility resources.
} 


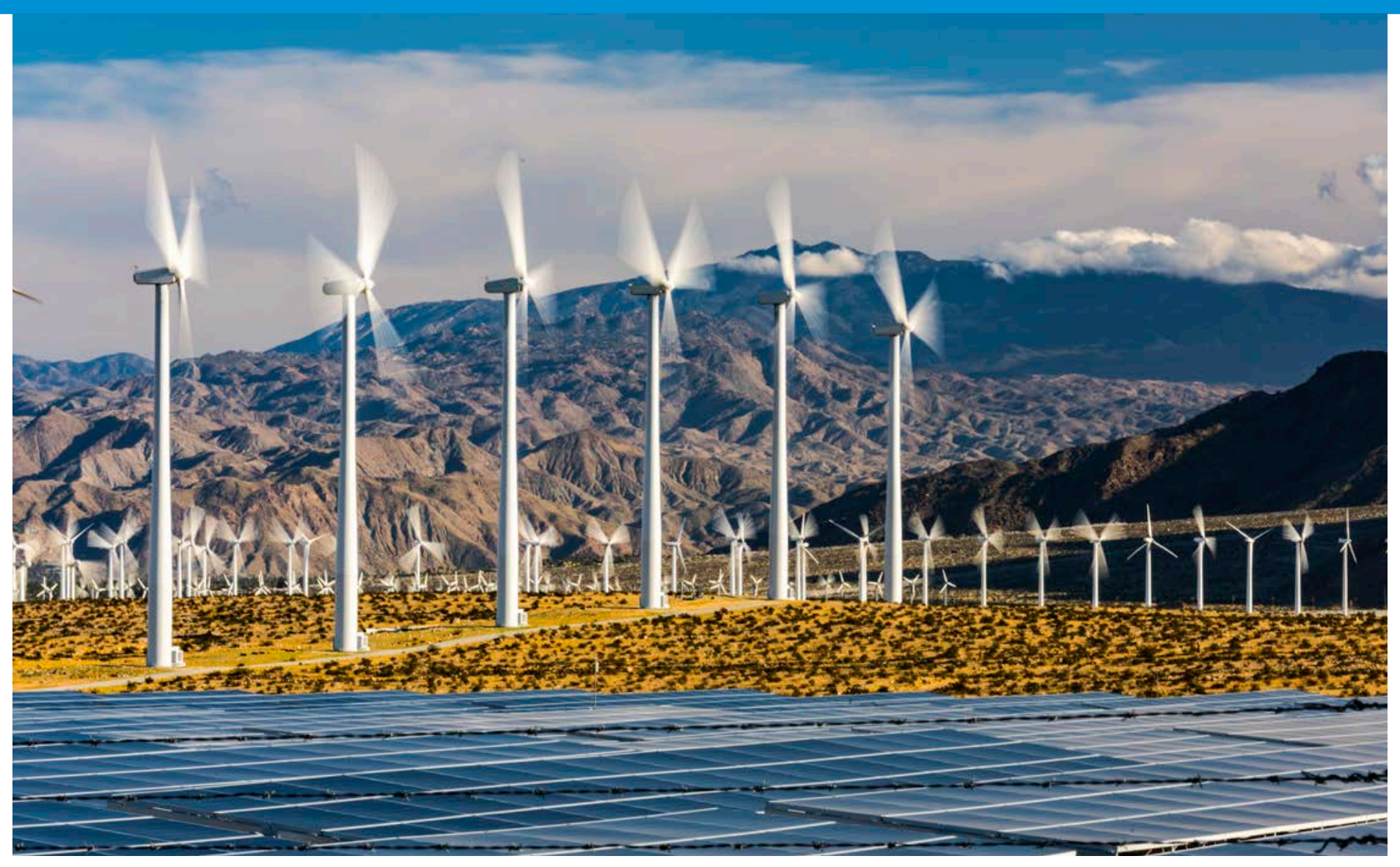

\section{Moving Forward Inclusively with Power System Transformation}

\section{In the Face of New Technologies and Evolving Power System}

Requirements, New Administrative Efforts are Likely Needed to Ensure Power System Transformation is Fair and Inclusive

Allowing competition from all technologies without picking winners or losers-often referred to as "technology neutrality" - is a common goal of decision makers overseeing PST with key system-wide, attribute-based goals. This principle endeavors to "future proof" regulations, allow innovation to easily enter the power market, and promote competition and market efficiency by ensuring that all resources can participate and seek remuneration for the value they provide. Importantly, modern power system resources-such as demand response, electricity storage, or variable renewable energy-have novel characteristics of cost structures, services offered, reliability, and, at times, ownership. Their introduction into the power system may thus require new administrative efforts to enable their participation in the power system and allow PST to proceed in support of stated goals. Furthermore, as power system operational requirements evolve to prioritize new system services (e.g., power system flexibility), maintaining technology neutrality may also necessitate the introduction of novel pricing mechanisms to value these services and ensure that all resources—both legacy and modern—can be remunerated fairly for providing them.

To begin, decision makers may need to ensure that legal frameworks and connection codes allow for the participation of modern power system resources, and that market 
and regulatory frameworks allow them to seek remuneration for their services. ${ }^{11}$ Electricity storage, for instance, can provide a range of valuable system services to utilities, transmission operators, and end use customers. In practice, however, storage resources are frequently limited by regulatory barriers as to which "market segment" they can participate in, which artificially limits the financial attractiveness of storage investments. In addition, many power markets do not allow aggregated DERs to provide services, either through wholesale power markets or directly to utilities. In these circumstances, new administrative efforts may be required to allow their participation. Particularly in the case of DERs, decision makers and their supporting regulatory institutions may need to undertake additional efforts to ensure that sufficient consumer and distribution network data are available to animate a DER aggregation market. Just as power plant developers seek market data to evaluate the viability of their projects, decision makers can help to ensure that DER providers obtain the data they desire, even though new administrative efforts may be required to ensure these data are collected in the first place, and also to balance consumer privacy concerns with a desire for market animation.

\section{Power System Transformation Efforts Can Promote More Socially Equitable Development}

Although PST can be an engine of economic growth, it may also lead to structural changes that disproportionately impact certain local economies. Global experience suggests that PST often involves a shift toward the use of a larger number of smaller and geographically distributed power system resources; in other words, large centralized thermal power plants are increasingly being retired in lieu of a more economically competitive and geographically diverse portfolio of smaller-scale wind, solar, natural gas, and battery energy storage resources, as well as more customer-sited DERs. Continued government investment and technological innovation in the realm of small modular nuclear reactors-and in the United States, small modular coal plants (US-DOE 2019)_further reflects the market trend toward resource modularization and geographic decentralization. Local economies that have a strong dependence on a large power plant or energy extraction operation may be negatively impacted by PST, even if power sector jobs overall experience significant growth. As energy sector infrastructure assets continue to decentralize, there will be a diversity of costs and benefits experienced by different communities that decision makers may need to consider. Proactively balancing stakeholder impacts and needs will thus be an important undertaking during PST efforts.

For decision makers to address such scenarios equitably, a good first step is to conduct a situational assessmentspecifically, a geographically detailed analysis that informs how the power plant fleet may change over time. Which plants (or supporting extraction operations) may be at risk of closure in the near- to mid-term, how many workers do these enterprises employ, and how resilient is the local economy to absorb these job losses? Answers to these questions can inform local economic development plans and shape decisions to promote a socially just transition. The economic development toolkit for decision makers is wide-ranging, but also highly context-specific. Solutions may range from affecting change at the individual level (e.g., direct job retraining or placement services) to the system level (e.g., implementation of strategic economic diversification strategies). In the long run, the trend toward decentralization may lead to more broad-based and resilient local economic growth, where the future loss of a large power sector enterprise is less likely to significantly depress local economies.

Policymakers may also be able to take steps to more directly ensure that local communities who host newly constructed power plants can benefit from their development. One quintessential example of such strategies

\footnotetext{
${ }^{11}$ As mentioned in Principle \#7, auction regulations in Chile required modifications before wind and solar energy could participate. This type of change precisely illustrates the need for regulatory frameworks to adapt to new technological developments in order to ensure "technology neutrality."
} 
is the South Africa Renewable Energy Independent Power Producer Procurement Programme, in which the Government of South Africa awards projects to preferred bidders partially based on their proposals to contribute to local economic development. Projects that win bids must commit to spending a certain percentage of their generated revenue on local socioeconomic and enterprise development projects, share ownership in the company with the local community, and ensure that local community members are hired as staff if feasibly possible. Such an arrangement helps to ensure that local communities affected by the project receive both immediate and longer term benefits from their participation (WWF 2015). The Chilean government is similarly encouraging the development of new energy generation projects with a "sharedvalue approach" that seeks to foster the development of initiatives that yield benefits for both project developers and local communities (Chilean Ministry of Energy 2018).

\section{Concluding Remarks}

Power sector policymakers in emerging economies face a complex landscape of issues and opportunities in their pursuit of PST pathways. Ensuring that transitions are holistically approached, effectively coordinated, and employing best practice policy instruments is a significant undertaking. Each country begins from its own unique starting point because each one's legacy power system has grown out of its own history, culture, geography, and endowment of natural resources. But international experience reveals some evolutionary principles common to all countries: the creative destruction induced by new technologies; the need to make investment of scarce capital as productive as possible; equity and universal access; and ensuring that the social allocation of costs is consistent with the distribution of social benefits, to name a few. International engagement in established forums such as CEM can help policymakers understand how others have addressed such issues, so that they can prioritize actions and implement solutions that work for their own transforming power systems.

\section{TEXT BOX 3: What is the 21 $1^{\text {st }}$ Century} Power Partnership?

The $21^{\text {st }}$ Century Power Partnership is a multilateral initiative of the Clean Energy Ministerial, with active membership and participation from the governments of Brazil, China, Denmark, Finland, India, Mexico, South Africa, and the United States. ${ }^{12}$ The Partnership supports national and regional efforts to advance power sector transformation, focusing on the development and dissemination of knowledge, bolstering of expert capacity, and directly supporting policy and regulatory implementation in member countries through technical assistance programs. Currently, the Partnership operates technical assistance programs in Mexico, India, South Africa, and China, with an emerging program of work in Brazil. The initiative makes continued efforts to capture and codify the various practical insights into power sector transformation that it yields through its country technical assistance activities, and has produced numerous publications over the years, including:

Status of Power System Transformation 2018 Advanced Power Plant Flexibility

Status of Power System Transformation 2017 System Integration and Local Grids

Next-generation Performance-based Regulation: Emphasizing Utility Performance to Unleash Power Sector Innovation

Clean Restructuring: Design Elements for Low-Carbon Wholesale Markets and Beyond

Status Report on Power System Transformation 2015

Power Systems of the Future

Flexibility in $21^{\text {st }}$ Century Power Systems

Integrating Variable Renewable Energy in Electric Power Markets: Best Practices from International Experience

${ }^{12}$ U.S. participation is currently under review. 


\section{References}

21CPP (21 $1^{\text {st }}$ Century Power Partnership). 2012. Integrating Variable Renewable Energy in Electric Power Markets: Best Practices from International Experience. Available at: https://www.nrel.gov/docs/fy12osti/53732.pdf

21CPP. 2015. Power Systems of the Future. NREL/TP-6A20-62611. Available at: https://www.nrel.gov/docs/fy15osti/62611.pdf

21CPP and IEA. 2018. Status of Power System Transformation 2018: Advanced Power Plant Flexibility. OECD. Paris, France. Available at: https://webstore.iea.org/ status-of-power-system-transformation-2018

21CPP and IEA (2019). Status of Power System Transformation 2019: Power System Flexibility. OECD. Paris, France. Available at: https://webstore.iea.org/ status-of-power-system-transformation-2019

21CPP and RAP. (21CPP and Regulatory Assistance Project). 2017. Next-Generation Performance Based Regulation Emphasizing Utility Performance to Unleash Power Sector Innovation. NREL/TP-A650-68512. Available at: https://www.nrel.gov/docs/fy17osti/68512.pdf

Besant-Jones, John E. 2006. Reforming Power Markets in Developing Countries: What Have We Learned? Washington, DC: World Bank. Available at: http://siteresources.worldbank. org/INTENERGY/Resources/Energy19.pdf

CEM (Clean Energy Ministerial). 2015. Joint Statement of the CEM Power System Challenge. Merida, Mexico: Clean Energy Ministerial. Available at: https://www.cleanenergyministerial.org/ sites/default/files/2018-07/CEM6-CEMPowerSystemChallengeJointStatement.pdf

CEM. 2018. Power System Flexibility Campaign Brochure. Copenhagen, Denmark: Clean Energy Ministerial. Available at: http://www.cleanenergyministerial.org/sites/default/files/201901/PSF_Brochure_190115_0.pdf

Chilean Ministry of Energy. 2018. Ruta Energética 2018-2022: Liderando la Modernización con Sello Ciudadano. Available at: http://www.mienergia.cl/centro-de-recursos/ruta-energetica-2018-2022-liderando-la-modernizacion-con-sello-ciudadano.

CNE (Comisión Nacional de Energía). 2018. Anuario Estadístico de Energía 2017. Available at: http://energiaabierta. $\mathrm{cl} /$ ?lang=\&s=anuario\%20estadistico\&t=reportes.
Couture, T., Cory, K., Kreycik, C., and Williams, E. 2010. A Policymaker's Guide to Feed-in Tariff Policy Design. National Renewable Energy Laboratory. NREL/TP-6A2-44849. Available at: https://www.nrel.gov/docs/fy10osti/44849.pdf.

CSIR (Council for Scientific and Industrial Research). 2017. Formal comments on the Integrated Resource Plan (2017): Update Assumptions, Base Case and Observations. CSIR. Pretoria, South Africa. Available at: https://www.csir.co.za/sites/ default/files/Documents/20170331CSIR_EC_DOE.pdf

Eberhard, A., and Naude, R. 2016. "The South African Renewable Energy Independent Power Producer Procurement Programme: A review and lessons learned." Journal of Energy in Southern Africa, Vol No. 4, pp 1-14. Available at: http://www.scielo.org.za/scielo.php?script=sci_abstract\&pid=S1 021-447X2016000400001\&lng=en\&nrm=iso

EPE (Empresa de Pesquisa Energética). 2018. Plano Decenal de Expansão de Energia 2027. Available at: http://www.epe. gov.br/pt/publicacoes-dados-abertos/publicacoes/plano-decenal-de-expansao-de-energia-2027. [in Portuguese]

FOR (Forum of Regulators). 2018. Sub-Group Report on Introduction of Five Minutes Scheduling, Metering, Accounting, and Settlement in Indian Electricity Market. Available at: http://erpc.gov.in/wp-content/uploads/2017/03/Sub-GroupReport-on-5-Min-Scheduling.pdf.

GTG (Greening the Grid). 2016. Big, Fast, and Flexible: Grid Operations for Efficient Variable Renewable Integration. Available at: https://greeningthegrid.org/trainings-1/webinars/ facilitating-the-integration-of-renewable-energy-through-balancing-area-cooperation-1.

Hall, D., Lobina, Emanuele, and de la Motte, Robin. 2005. "Public Resistance to Privatisation in Water and Energy." Development in Practice, 15(3/4), 286-301. Available at: https://www.jstor.org/ stable/4029962

IEA-RETD (International Energy Agency-Renewable Energy Technology Deployment). 2016. RE-TRANSITION - Transitioning to Policy Frameworks for Cost-Competitive Renewables. IEA Technology Collaboration Program for Renewable Energy Technology Deployment, Utrecht. Available at: http://iea-retd. org/wp-content/uploads/2016/03/IEA-RETD_RE-TRANSITION.pdf 
IRENA (International Renewable Energy Agency). 2017. Planning for the Renewable Future: Long-term Modelling and Tools to Expand Variable Renewable Power in Emerging Economies. IRENA, Abu Dhabi. Available at: https://www.irena.org/publications/2017/Jan/Planning-for-the-renewable-future-Long-termmodelling-and-tools-to-expand-variable-renewable-power

IRENA. 2018. Renewable Energy Auctions: Cases from Sub-Saharan Africa. IRENA, Abu Dhabi. Available at: https://www.irena.org/publications/2018/Apr/ Renewable-energy-auctions-Cases-from-sub-Saharan-Africa

NDRC (National Development and Reform Commission). 2016. China 13th Renewable Energy Development Five-Year Plan (2016-2020). NDRC. Beijing, China.

SA-DOE (South Africa Department of Energy). 2018. Renewable energy independent power producer (REIPP) agreements will benefit South Africa in the transition to an environmentally sustainable economic future. Opinion Piece by Minister Jeff Radebe, 27 July 2018. SA-DOE, Pretoria. Available at: http://www.energy.gov.za/IPP/CityPress-Opinion-PieceRenewable-Energy.pdf

SA-PBO (South Africa Parliamentary Budget Office). 2017. Analysis of Eskom's Financial Position: Full Report, SA-PBO, Pretoria. Available at: https://www.parliament.gov.za/storage/ app/media/PBO/Analysis_of_Eskom_finances_Report_to_ SCOA_presented_8_March_2017.pdf

SENER (Secretaría de Energía). 2019. Consejo Consultivo para la Transición Energética. Available at: https://www.gob.mx/sener/acciones-y-programas/ consejo-consultivo-para-la-transicion-energetica.

UNU-WIDER and JISEA (United Nations University and Joint Institute for Strategic Energy Analysis). 2017. The Political Economy of Clean Energy Transitions. Edited by Douglas Arent, Channing Arndt, Mackay Miller, Finn Tarp, and Owen Zinaman. Oxford University Press. ISBN: 978-0-19-880224-2. Available at: https://global.oup.com/academic/product/the-political-economy-of-clean-energy-transitions-9780198802242?cc=us\&lang=en\&

US-DOE (United States Department of Energy). 2019. Department of Energy Announces \$100M in Investments in Coal FIRST. Available at: https://www.energy.gov/articles/ department-energy-announces-100m-investments-coal-first.
World Bank. 2004a. Reforming Infrastructure: Privatization, Regulation, and Competition. Washington, DC. Available at: http://documents.worldbank.org/curated/en/709301468779183 565/310436360_20050007115940/additional/289850PAPEROreforming0infrastructure.pdf

World Bank. 2004b. Some Options for Improving the Governance of State-Owned Electricity Utilities. Washington, DC. Available at: http://citeseerx.ist.psu.edu/viewdoc/ download?doi=10.1.1.688.6990\&rep=rep1\&type=pdf

World Bank. 2017. Cost Recovery and Financial Viability of the Power Sector in Developing Countries: A Literature Review. Washington, DC. Available at: http://documents. worldbank.org/curated/en/896141513777558023/Costrecovery-and-financial-viability-of-the-power-sector-indeveloping-countries-a-literature-review

WWF (World Wildlife Fund). 2015. A review of the local community development requirements in South Africa's renewable energy procurement programme. https://www0.sun.ac.za/cst/ wp-content/uploads/2017/04/WWF_Wlokas_Review-of-localcommunity-development-in-REIPPP_2015.pdf.

\section{Notice}

This work was authored, in part, by the National Renewable Energy Laboratory, operated by Alliance for Sustainable Energy, LLC, for the U.S. Department of Energy (DOE) under Contract No. DE-AC3608GO28308, and the Hewlett Foundation within the framework of the 21st Century Power Partnership under ACT-16-12. The views expressed in the article do not necessarily represent the views of the DOE or the U.S. Government or any agency thereof.

This report is available at no cost from the National Renewable Energy Laboratory (NREL) at www.nrel.gov/publications.

U.S. Department of Energy (DOE) reports produced after 1991 and a growing number of pre-1991 documents are available free via www.OSTI.gov. 


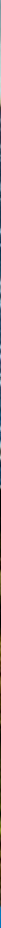

\section{www.21stCenturyPower.org}

The 21st Century Power Partnership is a multilateral effort of the Clean Energy Ministerial and serves as a platform for public-private collaboration to advance integrated policy, regulatory, financial, and technical solutions for the large-scale deployment of clean energy in combination with deep energy efficiency and smart grid solutions.

\section{CLEAN ENERGY} M I N I S T E R I A L Advancing Clean Energy Together

NREL/TP-6A20-73931 | Contract No. DE-AC36-08GO28308 | May 2019 NREL prints on paper that contains recycled content. Front and back photos from iStock 545378314; page 3: iStock 183784993 page 7: Dennis Schroeder, NREL 47213; page 11: iStock 943963912 